\title{
Fabrication of silver nanoparticles doped in the zeolite framework and antibacterial activity
}

This article was published in the following Dove Press journal:

International Journal of Nanomedicine

9 February 20II

Number of times this article has been viewed

\author{
Kamyar Shameli' \\ Mansor Bin Ahmad' \\ Mohsen Zargar ${ }^{2}$ \\ Wan Md Zin Wan Yunus' \\ Nor Azowa Ibrahim' \\ 'Department of Chemistry, Faculty \\ of Science, Universiti Putra Malaysia, \\ Selangor, Malaysia; ${ }^{2}$ Department \\ of Biology, Islamic Azad University, \\ Qum Iran
}

\begin{abstract}
Using the chemical reduction method, silver nanoparticles (Ag NPs) were effectively synthesized into the zeolite framework in the absence of any heat treatment. Zeolite, silver nitrate, and sodium borohydride were used as an inorganic solid support, a silver precursor, and a chemical reduction agent, respectively. Silver ions were introduced into the porous zeolite lattice by an ion-exchange path. After the reduction process, Ag NPs formed in the zeolite framework, with a mean diameter of about 2.12-3.11 nm. The most favorable experimental condition for the synthesis of Ag/zeolite nanocomposites (NCs) is described in terms of the initial concentration of $\mathrm{AgNO}_{3}$. The $\mathrm{Ag}$ /zeolite NCs were characterized by ultraviolet-visible spectroscopy, powder X-ray diffraction, transmission electron microscopy, scanning electron microscopy, energy dispersive X-ray fluorescence, and Fourier transform infrared. The results show that Ag NPs form a spherical shape with uniform homogeneity in the particle size. The antibacterial activity of Ag NPs in zeolites was investigated against Gram-negative bacteria (ie, Escherichia coli and Shigella dysentriae) and Gram-positive bacteria (ie, Staphylococcus aureus and methicillin-resistant Staphylococcus aureus) by disk diffusion method using Mueller-Hinton agar at different sizes of Ag NPs. All of the synthesized Ag/zeolite NCs were found to have antibacterial activity. These results show that Ag NPs in the zeolite framework can be useful in different biological research and biomedical applications.
\end{abstract}

Keywords: silver nanoparticles, zeolite, antibacterial activity, Mueller-Hinton agar, transmission electron microscopy

\section{Introduction}

Currently, the significance of nanoparticles (NPs) and their use in several industries has led to many investigations. Nanoscale metals demonstrate dissimilar characteristics in comparison with their bulk metal states. In the midst of various NPs, transition metals are attractive because of their exclusive physicochemical properties. ${ }^{1}$ Metal silver (Ag), as a transition element, has many applications in the fields of medicine, dentistry, clothing, catalysis, mirrors, optics, photography, electronics, and food industries. ${ }^{2}$ Moreover, introducing single NPs into other substrates results in a system with novel exploits. These classifications are described as nanocomposites (NCs). ${ }^{3}$ There are different types of NCs depending on the phases of constituents, eg, metal/polymer, ${ }^{4}$ metal/metal, ${ }^{5}$ metal/metal oxides,${ }^{6}$ metal/clay, ${ }^{7,8}$ and metal/zeolite. ${ }^{9}$ NC properties depend on the properties of single constituents, particle size, shape, and surface interaction. NCs allow us to have different properties in one place; the rigidity and corrosion resistance of metals such as silver can be enhanced through their use. As a porous material, zeolite is a superior candidate for compliant Ag NPs.
Correspondence: Kamyar Shameli Department of Chemistry, Faculty of Science, Universiti Putra Malaysia, 43400, Serdang, Selangor, Malaysia Tel +60389466044

Fax +60389466043

Email kamyarshameli@gmail.com 
Nanoporous crystals in the zeolite framework help us to control the particle size and to have a uniform distribution of Ag NPs on the internal surface. ${ }^{1,9}$ The potential of Ag/zeolite $\mathrm{NCs}$ is worth further study.

Zeolites are porous crystalline hydrated sodium aluminosilicate materials made of $\mathrm{MO}_{4}(\mathrm{M}=\mathrm{Si}$ and $\mathrm{Al})$ hexagonal connections by oxygen atoms with numerous channels and pores. There are water molecules and different cations in the porous structures of zeolite frameworks. ${ }^{10}$ The cations balance the negative charge of the zeolite lattice. Also, due to the easy heating of the zeolite structure, water molecules can be removed from the lattice. The zeolite has comparatively high ion-exchange ability and lattice stability; as a result, many studies have been done on its structure and its interactions with different cations. For the cation exchange of silver ions in the zeolite structure, we can employ general techniques using an $\mathrm{AgNO}_{3}$ solution. Therefore, $\mathrm{AgNO}_{3} /$ zeolite reduces the $\mathrm{Ag}$ /zeolite NCs using different methods, such as chemical reducing agents (eg, hydrazine hydrate), ${ }^{11}$ hydrogen gases, ${ }^{12}$ heat treatment, ${ }^{13}$ hydrocarbons, ${ }^{14}$ or sonoand photochemical reduction. ${ }^{15}$

Researchers have shown that certain devised metal NPs have superior antibacterial activity and that antimicrobial formulations comprising NPs could be efficient bactericidal materials. Among inorganic antibacterial agents, transition metals (especially silver) have been used most widely for anti-infection drugs. ${ }^{16}$ The antibacterial and antiviral actions of $\mathrm{Ag} \mathrm{NPs}, \mathrm{Ag}^{+}$, and silver composites have been thoroughly investigated. ${ }^{17,18}$ In low concentrations, silver is nontoxic to human cells. The epidemiological history of silver has recognized its nontoxicity in ordinary employment. ${ }^{19}$ The Ag NPs demonstrate excellent antibacterial activity by binding to microbial DNA, avoiding bacterial duplication, and preventing metabolic enzymes of the bacterial electron transport chain, causing their inactivation. ${ }^{20}$ Thus, Ag NPs have been used in an extensive range of medical products such as burn dressings, scaffolds, dental resin composites, water purification systems, and anti-HIV-I virus and in medical device coatings. ${ }^{2}$

In this study, the spherical structure of Ag NPs was synthesized into the cavities of the zeolite framework using $\mathrm{AgNO}_{3}$ and sodium borohydride as the silver precursor and reducing agent, respectively. We used zeolite with mean diameters of 2.12-3.11 nm to prevent the Ag NPs from aggregating. In addition, the antibacterial activities of $\mathrm{AgNO}_{3} /$ zeolite and $\mathrm{Ag} /$ zeolite $\mathrm{NCs}$ were investigated and compared. We were able to obtain Ag NPs with different sizes and antibacterial activities by controlling the $\mathrm{AgNO}_{3}$ concentration. To the best of our knowledge, there has not been any report of the synthesis and antibacterial activity of $\mathrm{Ag} /$ zeolite NCs using a chemical reduction method.

\section{Materials and methods Materials}

All reagents in this work were of analytical grades and used as received without further purification. In particular, $\mathrm{AgNO}_{3}(99.98 \%$ ) was supplied by Merck KGaA (Darmstadt, Germany), and the $\mathrm{NaBH}_{4}(98.5 \%)$ and the $\mathrm{Na}^{+}$-Y-zeolite powder $\leq 45 \mu \mathrm{m}$ with a molar ratio of $\mathrm{SiO}_{2} / \mathrm{Al}_{2} \mathrm{O}_{3}$ of 4.5 were obtained from Sigma-Aldrich (St Louis, MO, USA). All aqueous solutions were used with double-distilled water.

\section{Synthesis of Ag/zeolite NCs by using $\mathrm{NaBH}_{4}$}

For the synthesis of $\mathrm{Ag} /$ zeolite NCs, the silver contents of the samples were 0.5 (A1), 1.0 (A2), 1.5 (A3), 2.0 (A4), and $5.0 \mathrm{~g}$ (A5) Ag/100 g zeolite. Constant amounts of zeolite were suspended in different volumes of $1 \times 10^{-3} \mathrm{M} \mathrm{AgNO}_{3}$ solution and stirred for 24 hours at room temperature to obtain the $\mathrm{AgNO}_{3} /$ zeolite suspensions and completed cation exchange. A freshly prepared $\mathrm{NaBH}_{4}\left(4 \times 10^{-2} \mathrm{M}\right)$ solution was then added to the suspensions under continuous stirring to reach a constant $\mathrm{AgNO}_{3} / \mathrm{NaBH}_{4}$ molar ratio (1:4). After the addition of the reducing agent, stirring continued for 1 hour. The obtained suspensions of Ag/zeolite NCs were then centrifuged, washed four times using the double-distilled water in order to remove the silver ion residue, and dried overnight at $40^{\circ} \mathrm{C}$ under vacuum. All experiments were conducted at laboratory room temperature.

\section{Evolution of antibacterial activity}

The in vitro antibacterial activity of the samples was evaluated by the disk diffusion method using Mueller-Hinton agar (MHA) with determination of inhibition zones in millimeters $(\mathrm{mm})$, which conformed to the recommended standards of the National Committee for Clinical Laboratory Standards (NCCLS; now renamed Clinical and Laboratory Standards Institute [CLSI], 2000). Escherichia coli (ATCC 25922), Shigella dysentriae (ATCC 9753), Staphylococcus aureus (ATCC 25923), and methicillin-resistant Staphylococcus aureus (MRSA) (ATCC 700689) were used for the antibacterial effect assay. Briefly, the sterile paper disks (6 mm) impregnated with $20 \mu \mathrm{l}$ of Ag/zeolite NCs (A2, A4, and A5) with different treatment times were suspended in the sterile distilled water and left to dry for 24 hours at $35^{\circ} \mathrm{C}$ in a sterile condition. The bacterial suspension was prepared by making a saline suspension of isolated colonies selected 
from the 18-24 hours of tryptic soy agar plate. The suspension was adjusted to match the tube of the 0.5 McFarland turbidity standards using the $600 \mathrm{~nm}$ spectrophotometer, which equals $1.5 \times 10^{8}$ colony-forming units $/ \mathrm{mL}$. The surface of MHA was completely inoculated using a sterile swab, which was steeped in the prepared suspension of bacterium. Finally, the impregnated disks were placed on the inoculated agar and incubated at $37^{\circ} \mathrm{C}$ for 24 hours. After incubation, the diameter of the growth inhibition zones was measured. Chloramphenicol $(30 \mu \mathrm{g})$ and cefotaxime $(30 \mu \mathrm{g})$ were used as the positive standards in order to control the sensitivity of the bacteria. All tests were done in triplicate.

\section{Characterization methods and instruments}

The prepared Ag/zeolite NCs were characterized using ultraviolet (UV)-visible spectroscopy, powder X-ray diffraction (PXRD), transmission electron microscopy (TEM), scanning electron microscopy (SEM), energy dispersive $\mathrm{X}$-ray fluorescence spectrometry (EDXRF), inductively coupled plasma-optical emission spectrometry (ICP-OES), and Fourier transform infrared (FT-IR) spectroscopy. The UV-visible spectra were recorded over the range of 300-700 nm using the Shimadzu UV-1650PC UV-visible spectrophotometer (Shimadzu, Kyoto, Japan). The structures of the produced Ag/zeolite NCs were examined using PXRD with the Shimadzu XRD-6000. The PXRD patterns were employed to determine the crystalline structure of synthesized Ag NPs in the wide angle range of $2 \theta\left(30^{\circ}<2 \theta<80^{\circ}\right)$. A wavelength $(\lambda)$ of $0.15418 \mathrm{~nm}$ was used for these measurements and recorded at a scan speed of $4 \% \mathrm{~min}^{-1}$. Moreover, TEM observations were carried out on a Hitachi H-7100 electron microscope (Hitachi High-Technologies Corporation, Tokyo, Japan), and the particle size distributions were determined using UTHSCSA Image Tool Version 3.00 program (UTHSCSA Dental Diagnostic Science, San Antonio, TX, USA). To study the morphology of zeolite and Ag/zeolite NCs (A2, A4, and A5), SEM was performed using the Philips XL-30 instrument. Furthermore, EDXRF was carried out on a Shimadzu EDX-700HS spectrometer. The elemental analysis of as-synthesized Ag NPs was quantified using ICP-OES model Optima 2000 DV (PerkinElmer, Waltham, MS, USA). Meanwhile, the FT-IR spectra were recorded over the range of $400-4000 \mathrm{~cm}^{-1}$ using the Series 100 PerkinElmer FT-IR 1650 spectrophotometer. After the reactions, the samples were centrifuged using a high-speed centrifuge machine (Avanti J25, Beckman Coulter, Inc., Brea, CA, USA).

\section{Results and discussion}

For the synthesis of Ag NPs via the chemical reduction method, it is important to choose a suitable reducing agent. In this research, the zeolite substrate was appropriate as solid support for reducing the $\mathrm{AgNO}_{3}$ /zeolite suspension by $\mathrm{NaBH}_{4}$. According to Equation 1, Ag NPs were synthesized into the structure of the zeolite. ${ }^{21}$

$$
\begin{aligned}
\mathrm{Ag}^{+} / \text {Zeolite }+\mathrm{BH}_{4}^{-}+3 \mathrm{H}_{2} \mathrm{O} \rightarrow & \mathrm{Ag}^{0} / \text { Zeolite }+\mathrm{B}(\mathrm{OH})_{3} \\
& +3.5 \mathrm{H}_{2} \uparrow
\end{aligned}
$$

The schematic illustration of the synthesis of $\mathrm{Ag} /$ zeolite $\mathrm{NCs}$ from $\mathrm{AgNO}_{3} /$ zeolite is depicted in Figure 1. Meanwhile, as shown in Figure 2, the $\mathrm{AgNO}_{3} /$ zeolite suspensions (A0) were colorless; after the addition of the reducing agent, however, they turned to light brown (A1 and A2), brown (A3), and dark brown (A4 and A5), indicating the formation of Ag NPs in the zeolite framework. The formation of Ag NPs was followed by measuring the surface plasmon resonance (SPR) band peaks of the $\mathrm{AgNO}_{3} /$ zeolite and $\mathrm{Ag}$ /zeolite $\mathrm{NCs}$ at the wavelength ranging from $300 \mathrm{~nm}$ to $700 \mathrm{~nm}$ (Figure 3 ). The PXRD patterns of zeolite and $\mathrm{Ag} / \mathrm{zeolite} \mathrm{NCs}$ (A1-A5) in the wide angle range of $2 \theta\left(5^{\circ}<2 \theta<80^{\circ}\right)$ were compared in order to determine the crystalline structures of the synthesized Ag NPs (Figure 4). The TEM images of zeolite and $\mathrm{AgNO}_{3}$ /zeolite do not show any particle size of the nanosilver; however, in the $\mathrm{Ag} /$ zeolite $\mathrm{NCs}$ (A2, A4, and A5), the mean diameter of the NPs ranged from about $2.12 \mathrm{~nm}$ to $3.11 \mathrm{~nm}$ (Figures 5 and 6). As shown in Figure 7, the SEM images indicated that there were no structural changes in the initial zeolite and $\mathrm{Ag}$ /zeolite $\mathrm{NCs}$ (A2, A4, and A5) at different $\mathrm{AgNO}_{3}$ concentrations. Additionally, the EDXRF spectra for the zeolite and Ag/zeolite NCs (A2, A4, and A5) confirmed the presence of elemental compounds in the zeolite and Ag NPs without any other impurity peaks. The chemical structures of zeolite and Ag/zeolite NCs (A2, A4, and A5) were analyzed using FT-IR spectroscopy (Figure 8). The approximate efficiency gradually increased from A1 to A5 (Table 1). The antibacterial studies showed comparatively similar effects for all samples, as indicated by the inhibition zone test between zeolite, $\mathrm{AgNO}_{3}$ /zeolite, and $\mathrm{Ag}$ /zeolite $\mathrm{NCs}$ (A2, A4, and A5) against different bacteria (Figure 9, Table 2).

\section{UV-visible spectroscopy}

The color of $\mathrm{AgNO}_{3} /$ zeolite suspensions during the reduction process using $\mathrm{NaBH}_{4}$ changed from colorless to different ranges of brown, which indicates the formation of Ag NPs in the zeolite as solid support. The silver SPR band peaks were detected around 394-401 nm (Figure 3). These absorption 
a

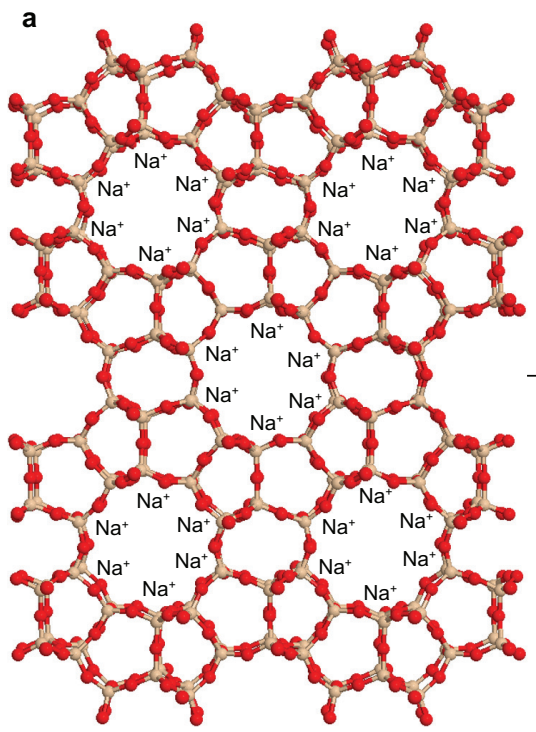

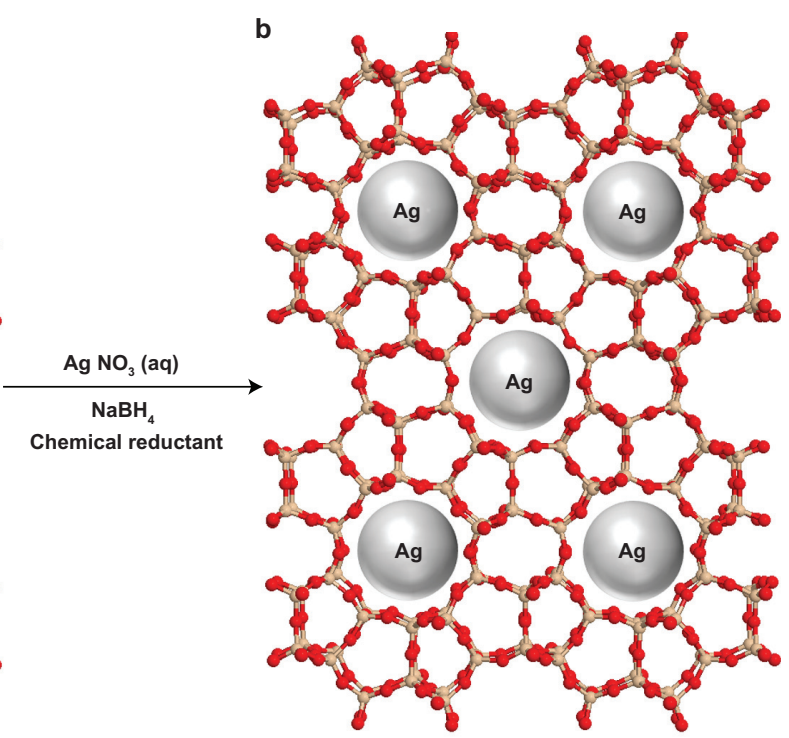

Figure I Schematic illustration of the synthesis of the silver nanoparticles into the zeolite framework by strong chemical reduction.

bands were assumed to correspond to Ag NPs smaller than $10 \mathrm{~nm} \cdot{ }^{22}$ Although there was no UV-visible absorption of Ag NPs before the addition of $\mathrm{NaBH}_{4}$ in $\mathrm{A} 0$ (Figure 3), the growth of the plasmon peak at $394 \mathrm{~nm}$ indicated the formation of Ag NPs in A1. Furthermore, the gradual increase in the $\mathrm{AgNO}_{3}$ concentration from $\mathrm{A} 1$ to $\mathrm{A} 4$ also increased the corresponding peak intensities in the range of 394, 401, 399, and $395 \mathrm{~nm}$, respectively. In A5, the absorption peak SPR band of Ag NPs was a constant wavelength (394 nm) due to the isometric size of the Ag NP structure. These results confirmed the wavelength ranges. In addition, the size of the NPs for all samples is approximately constant, without many changes.

\section{Powder X-ray diffraction}

The PXPD spectra of the zeolite supporting Ag NPs are shown in Figure 4. These spectra show 43 peaks at $7.42^{\circ}, 10.38^{\circ}, 12^{\circ}$, $60^{\circ}, 16.26^{\circ}, 20.58^{\circ}, 21.88^{\circ}, 24.18^{\circ}, 26.34^{\circ}, 27.32^{\circ}, 30.14^{\circ}$,

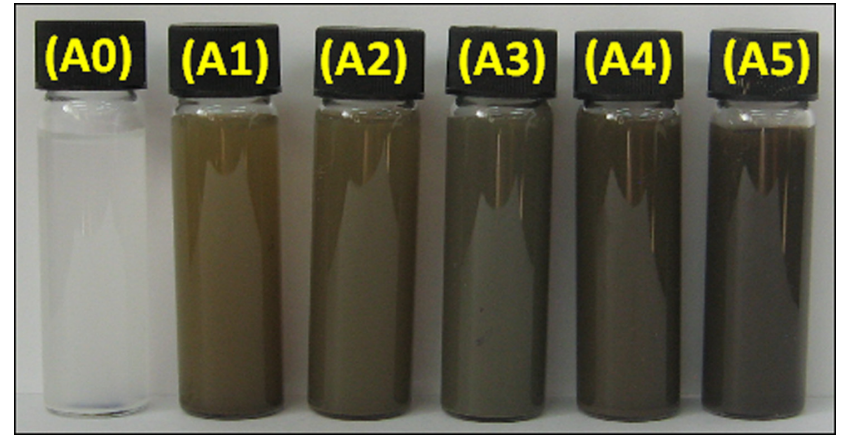

Figure 2 Photograph of $\mathrm{AgNO}_{3}$ /zeolite (A0) and $\mathrm{Ag}$ /zeolite nanocomposites at different $\mathrm{AgNO}_{3}$ concentrations: Al 0.5\%, A2 1.0\%, A3 1.5\%, A4 2.0\%, and A5 5.0\%. $31.04^{\circ}, 32.74^{\circ}, 33.24^{\circ}, 34.34^{\circ}, 35.94^{\circ}, 36.64^{\circ}, 37.76^{\circ}, 40.24^{\circ}$, $41.74^{\circ}, 41.92^{\circ}, 42.62^{\circ}, 43.58^{\circ}, 44.36^{\circ}, 47.50^{\circ}, 47.68^{\circ}, 49.04^{\circ}$, $49.62^{\circ}, 52.80^{\circ}, 54.48^{\circ}, 56.54^{\circ}, 57.58^{\circ}, 58.74^{\circ}, 60.18^{\circ}, 60.44^{\circ}$, $62.68^{\circ}, 64.26^{\circ}, 65.22^{\circ}, 66.54^{\circ}, 69.34^{\circ}, 71.10^{\circ}, 72.92^{\circ}, 75.96^{\circ}$, and $77.82^{\circ}$, which indicat the presence of zeolite as a stable substrate (PXRD zeolite Ref. 01-072-2344). As shown in Ag/zeolite, NCs (A1-A5) had a similar diffraction profile,

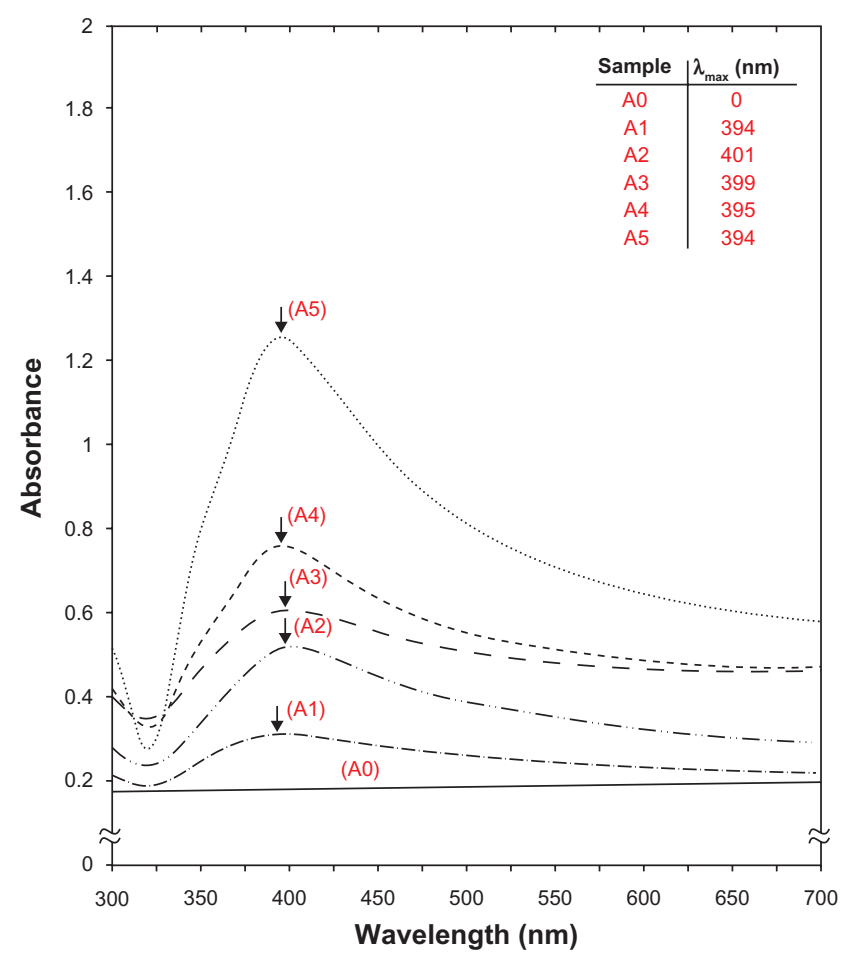

Figure 3 Ulraviolet-visible absorption spectra of silver/zeolite nanocomposites for different $\mathrm{AgNO}_{3}$ concentrations: Al 0.5\%, A2 I.0\%, A3 1.5\%, A4 2.0\%, A5 5\%, and $\mathrm{AO} \mathrm{AgNO}_{3}$ /zeolite in the absence of $\mathrm{NaBH}_{4}$. 


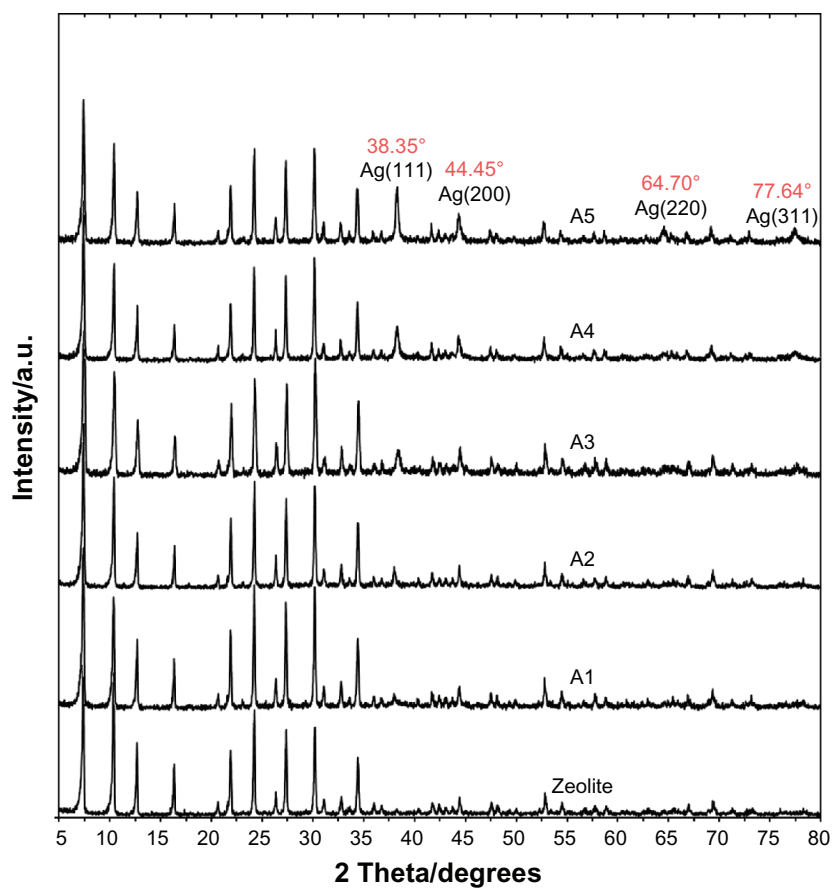

Figure 4 Powder X-ray diffraction patterns of zeolite and silver/zeolite nanocomposites for determination of nanosilver crystals at different $\mathrm{AgNO}$ concentrations $(0.5,1.0,1.5,2.0$, and $5.0 \%[\mathrm{Al}-\mathrm{A} 5])$.

and the PXRD peaks at $2 \theta$ of $38.35^{\circ}, 44.45^{\circ}, 64.70^{\circ}$, and $77.64^{\circ}$ could be attributed to the $111,200,220$, and 311 crystallographic planes of the face-centered cubic (fcc) silver crystals, respectively. For all samples, the main crystalline phase was silver, and no obvious other phases as impurities were found in the PXRD patterns (according to the silver standard diffraction pattern of Ref. 01-087-0717). The intensities of 111, 200, 220, and 311 reflections due to the Ag NP phase were also found to increase, along with the increased Ag NPs in the zeolite matrix by the chemical reduction method. Furthermore, the PXRD peak increases of Ag NPs were mostly due to the existing nanosized particles in the substrate. ${ }^{23}$

\section{Morphology}

Figure 5 shows the TEM images of zeolite after impregnation with aqueous $\mathrm{AgNO}_{3}$. These two images demonstrate zeolite and $\mathrm{AgNO}_{3}$ /zeolite but without any $\mathrm{Ag} \mathrm{NPs}$ (Figure 5A, B). Figure 6 shows TEM images and their corresponding particle size distributions of Ag/zeolite NCs (A2, A4, and A5) containing different percentages of Ag NPs. The TEM images and their size distributions reveal mean diameters and standard deviations of Ag NPs of about $2.12 \pm 0.37 \mathrm{~nm}$, $2.95 \pm 0.65 \mathrm{~nm}$, and $3.11 \pm 0.88 \mathrm{~nm}$ for $1.0 \%(\mathrm{~A}-\mathrm{B}), 2.0 \%$ (C-D), and $5.0 \%(\mathrm{E}-\mathrm{F})$, respectively. These results show that the uniform diameters of the Ag NPs synthesized in the isometric cavities of the zeolite depending on the initial $\mathrm{AgNO}_{3}$ concentration. Figure 7 presents the SEM images of the zeolite and Ag/zeolite NCs (A2, A4, and A5). The morphology of zeolite demonstrates a surface with a cubic shape, which is a typical structure for zeolite (Figure 7A). The exterior morphology for Ag/zeolite NCs (A2, A4, and A5) also shows cubic forms without significant morphological differences between them. Furthermore, the external surfaces of Ag/zeolite NCs gradually become shinier due to the presence and increase of Ag NPs concentrations (Figure 7A, C, $\mathrm{E}$, and $\mathrm{G})$. The EDXRF spectra for the zeolite show that the peaks around $1.49,1.65,2.38,2.55,2.86,3.22,4.54,5.52$, 6.47 , and $7.42 \mathrm{keV}$ are related to the binding energies of zeolite and peaks around 1.3, 3.1, 3.3, and $3.4 \mathrm{keV}$ related to silver elements in the A2, A4, and A5. ${ }^{24}$ Additionally, the EDXRF spectra for the zeolite and Ag/zeolite NCs confirm the presence of elemental compounds in the zeolite and $\mathrm{Ag}$ NPs without any impurity peaks. Moreover, Figure 7 demonstrates that with the increased percentages of Ag NPs in the zeolite substrate, the intensity of Ag NPs peaks in the EDXRF spectra also increased. The results indicate that the synthesized Ag NPs are of high purity.
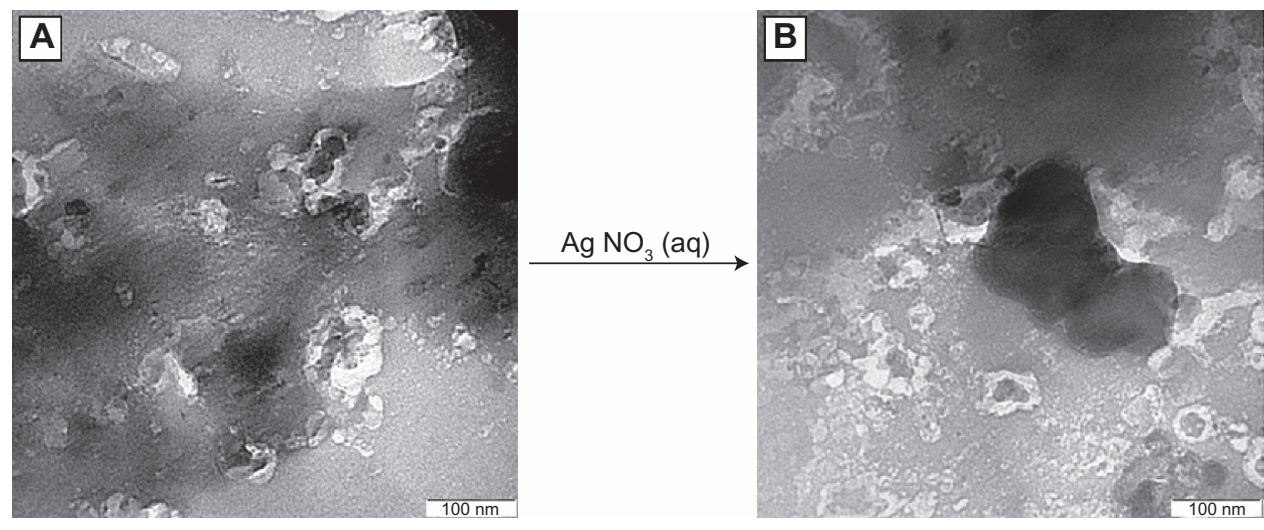

Figure 5 Transmission electron microscopy images of $\mathbf{A})$ zeolite and $\mathbf{B})$ zeolite after impregnation with aqueous $\mathrm{AgNO}_{3}(\mathrm{AgNO} / \mathrm{zeolite}[\mathrm{A0}])$. 

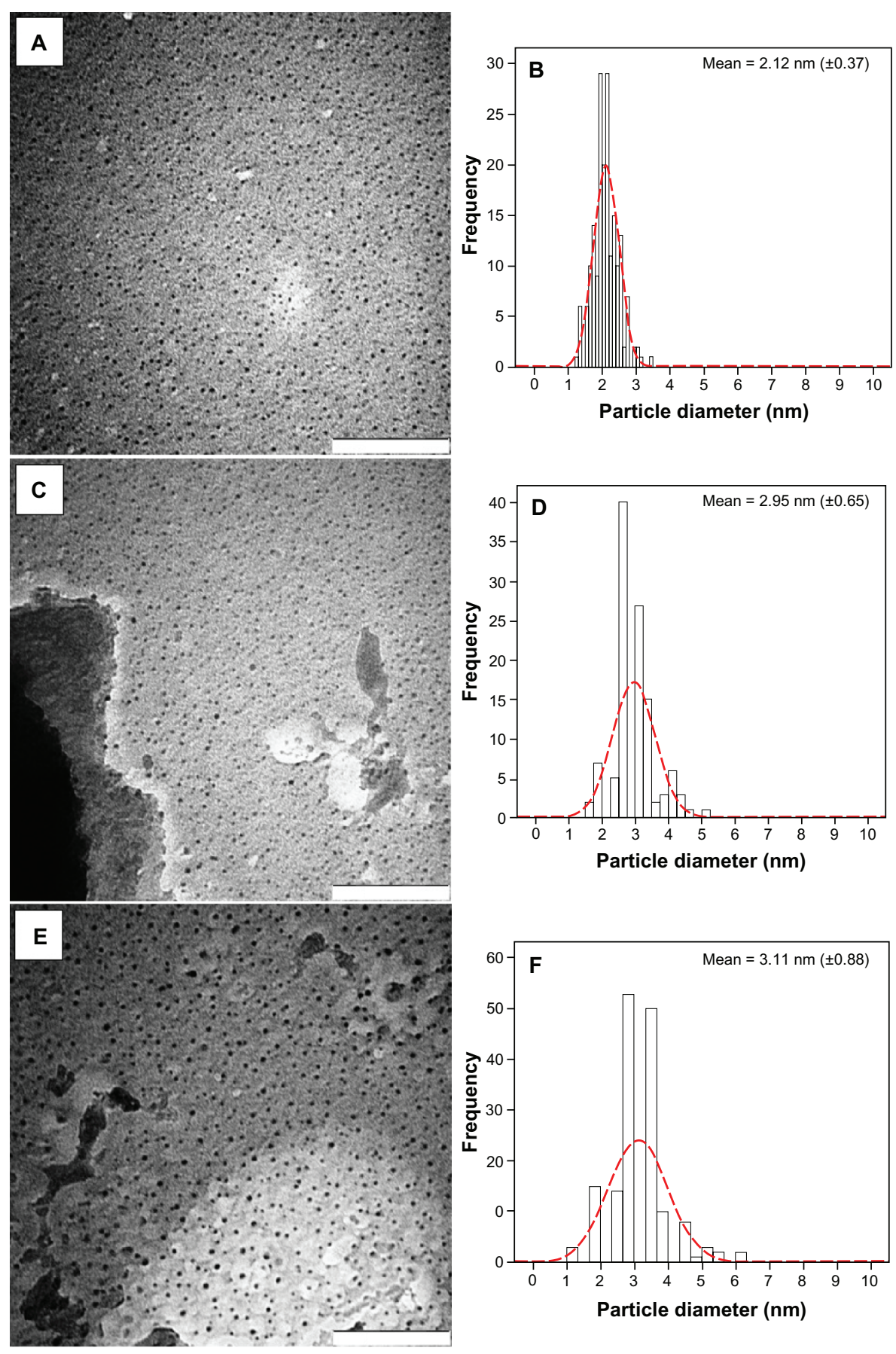

Figure 6 Transmission electron microscopy images and corresponding particle size distribution of silver/zeolite nanocomposites at different $\mathrm{AgNO}_{3}$ concentrations $\left(\mathrm{A}_{2} \mathrm{I} .0 \%\right.$ $[\mathbf{A}, \mathbf{B}], \mathrm{A} 42.0 \%[\mathbf{C}, \mathbf{D}]$, and A5 5.0\% [E, F])

\section{FT-IR chemical analysis}

Figure 8 shows compared FT-IR spectra for the silicate host structure of zeolite and $\mathrm{Ag} /$ zeolite NCs with different amounts of Ag NPs. The FT-IR spectrum of zeolite showed vibration bands at $3353 \mathrm{~cm}^{-1}$ for $\mathrm{O}-\mathrm{H}$ stretching due to the $\mathrm{H}_{2} \mathrm{O}$ interporous structure of $\mathrm{O}-\mathrm{H}$ stretching ( $\mathrm{H}$ bonding), and at $1646 \mathrm{~cm}^{-1}$ for $\mathrm{H}-\mathrm{O}-\mathrm{H}$ bending. The positions of the vibrational bands at $969-461 \mathrm{~cm}^{-1}$ corresponding to $\mathrm{Si}-\mathrm{O}$ and other interstructure bands remained unchanged; a strong band at $969 \mathrm{~cm}^{-1}$ was associated with the stretching vibration of $\mathrm{Si}-\mathrm{O}$, which usually suggests a three-dimensional silica phase. The band at $676 \mathrm{~cm}^{-1}$ was assigned to $\mathrm{Al}-\mathrm{O}$, and the position bands at $546-461 \mathrm{~cm}^{-1}$ were allocated to the $\mathrm{Si}-\mathrm{O}-\mathrm{Si}$ bending vibration. The FT-IR spectra indicated the 

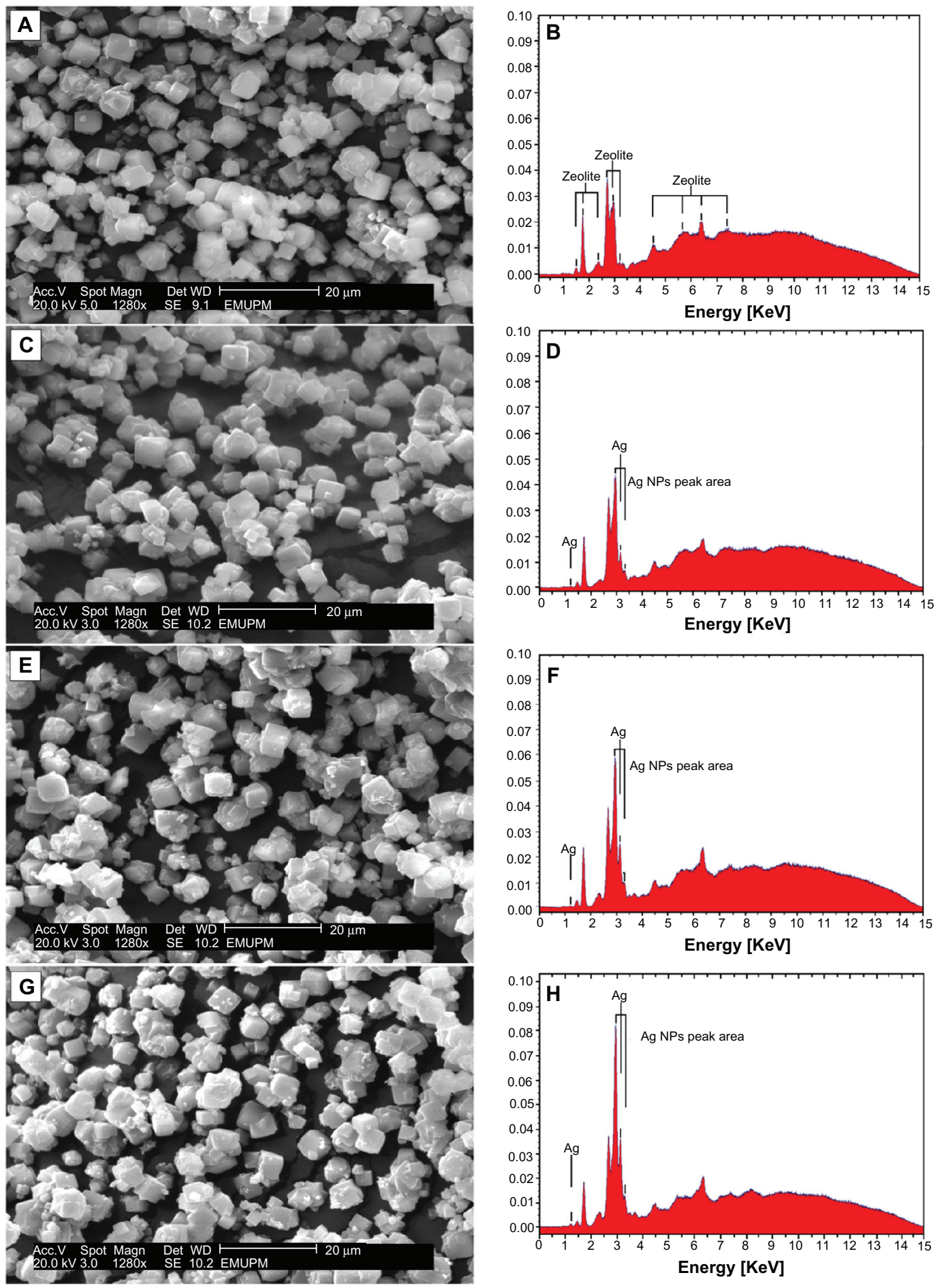

Figure 7 Scanning electron microscopy micrographs and energy dispersive X-ray fluorescence spectrometer spectra, respectively, for the zeolite (A, B) and silver/zeolite nanocomposites (A2 1.0\% [C, D], A4 2.0\% [E, F], and A5 5.0\% [G, H]).

rigidity of silicate structure and nonband chemical interaction between the zeolite structure and Ag NPs in Ag/zeolite NCs. The interactions between the zeolite and Ag NPs were associated with the peak at $3353 \mathrm{~cm}^{-1}$. A broad peak was due to the presence of van der Waals interactions between the hydroxyl groups in the zeolite structure related to $\mathrm{H}_{2} \mathrm{O}$ and the partial positive charge on the surface of Ag NPs. ${ }^{8}$ These peaks, with the enhanced Ag NPs in the Ag/zeolite NCs (A2, A4, and A5), shifted to low wave numbers, and the peak intensity decreased. 


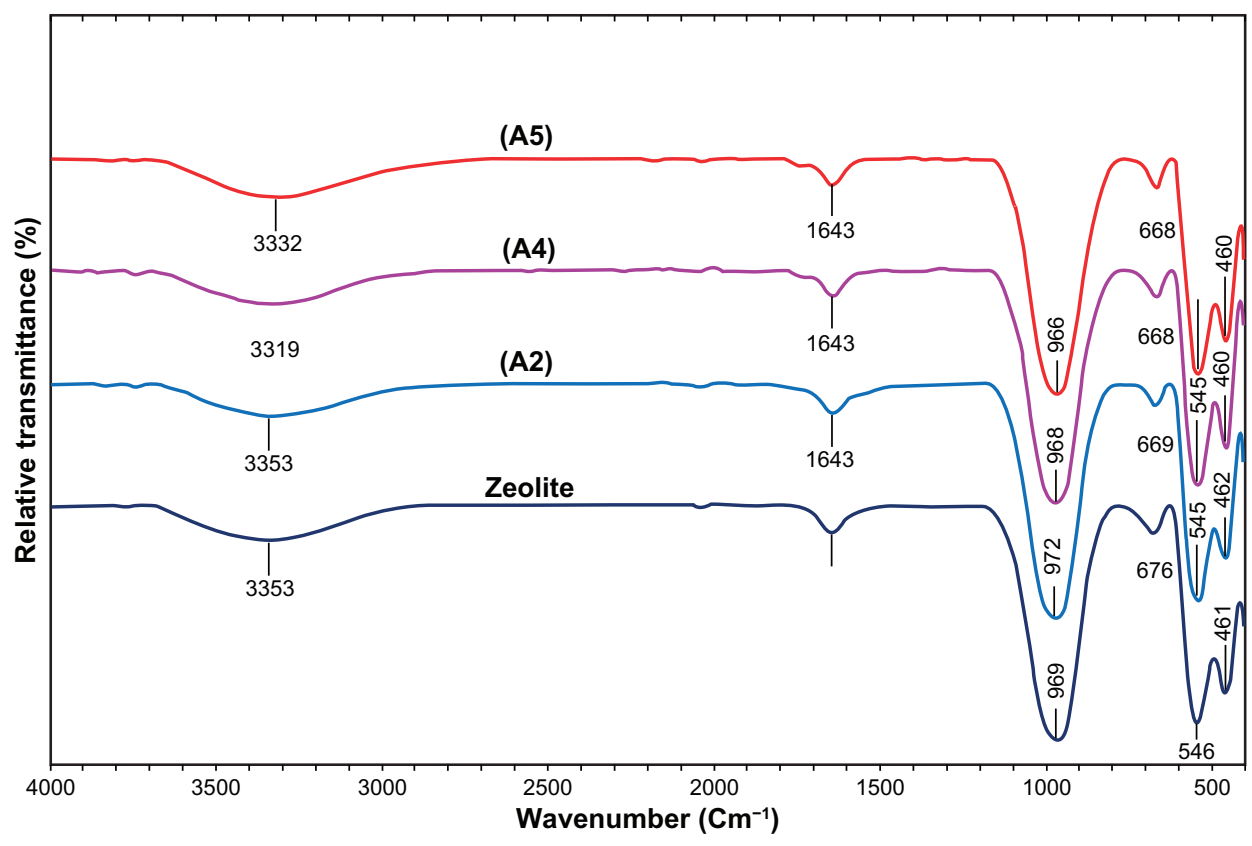

Figure 8 Fourier transform infrared spectra of zeolite and silver/zeolite nanocomposites (A2 1.0\%, A4 2.0\%, and A5 5.0\%).

\section{Inductively coupled plasma-optical emission spectroscopy}

To determine the efficiency of $\mathrm{AgNO}_{3} /$ zeolite suspension reduction to $\mathrm{Ag} /$ zeolite $\mathrm{NCs}$, the ICP-OES analyzer was used in this study. A modified digestion method was used to quantify the amount of $\mathrm{Ag} \mathrm{NP}$ conversion to $\mathrm{Ag}^{+}$in the zeolite. An air-dry mass of each Ag/zeolite NC (A1-A5) was submerged in a solution of $10 \mathrm{~mL}$ ultrapure reagent grade nitric acid (364576, Sigma-Aldrich, reagent grade $>90 \%$ ) and $10 \mathrm{~mL}$ double-distilled water. After the observed glasses were placed over the digestion beakers, the solutions were heated to approximately $80^{\circ} \mathrm{C}$ for 15 minutes and allowed to react. The digestion solutions were allowed to cool at room temperature and were then placed through a glass fiber filter (Qualitative 2, Whatman Ltd) and diluted in $100 \mathrm{~mL}$ in volumetric flasks. ${ }^{25}$ After detecting the silver ions using
ICP-OES spectroscopy, the approximate efficiency gradually decreased from 95.36 to $92.88,90.79,87.48$, and finally $80.96 \%$ (Table 1). The results from the ICP-OES analysis using a strong reduction agent confirm the formation of $\mathrm{Ag}$ NPs in zeolite, which produced high yields.

\section{Antibacterial activity}

Inhibition zone values were obtained for the synthesized $\mathrm{AgNO}_{3}$ /zeolite suspension and $\mathrm{Ag} /$ zeolite NCs (A2, A4, and A5) tested against E. coli, S. dysentriae, S. aureus, and MRSA. The results are presented as average values in Table 2 and as images in Figure 9. The $\mathrm{AgNO}_{3}$ and $\mathrm{Ag} \mathrm{NPs}$ in the zeolite framework showed antibacterial activity against Gram-negative and Gram-positive bacteria (Table 2). Because of their size, Ag NPs can easily reach the nuclear content of bacteria and present the greatest surface area;

Table I Physical properties of silver nanoparticles (Ag NPs) in Ag/zeolite synthesized at different $\mathrm{AgNO}_{3}$ concentrations: $\mathrm{Al}$ 0.5\%, A2 1.0\%, A3 1.5\%, A4 2.0\%, and A5 5.0\%

\begin{tabular}{|c|c|c|c|c|c|}
\hline Samples & $\begin{array}{l}\text { Reaction volume } \\
\text { (L) }\end{array}$ & $\lambda_{\max }^{a}$ & Absorbance $^{\mathrm{b}}$ & $\begin{array}{l}\text { Approximated efficiency } \\
\text { (\%) }\end{array}$ & $\begin{array}{l}\text { Ag NPs particle size } \\
(\mathrm{nm})\end{array}$ \\
\hline$\overline{\mathrm{AI}}$ & 0.50 & 394 & 0.33 & $95.36 \pm 1.21$ & $2.10 \pm 0.26$ \\
\hline $\mathbf{A 2}$ & 1.00 & 401 & 0.54 & $92.88 \pm 1.88$ & $2.12 \pm 0.37$ \\
\hline A3 & 1.50 & 399 & 0.62 & $90.79 \pm 2.76$ & $2.44 \pm 0.53$ \\
\hline A4 & 2.00 & 395 & 0.76 & $87.48 \pm 3.13$ & $2.95 \pm 0.65$ \\
\hline A5 & 5.00 & 394 & 1.27 & $80.96 \pm 6.56$ & $3.11 \pm 0.88$ \\
\hline
\end{tabular}

Notes: ${ }^{\mathrm{T}}$ The experiments were repeated three times and were averaged to give the data in Table I; ${ }^{\mathrm{T}}$ The data were obtained by multiplying the absorbance of the corresponding diluted solutions by their dilution factors when diluted solutions were used for the data; 'The size of $\mathrm{Ag} \mathrm{NPs} \mathrm{was} \mathrm{determined} \mathrm{by} \mathrm{measuring} \mathrm{diameters}$ of about $>100$ nanoparticles in transmission electron microscopy image and by averaging them. 


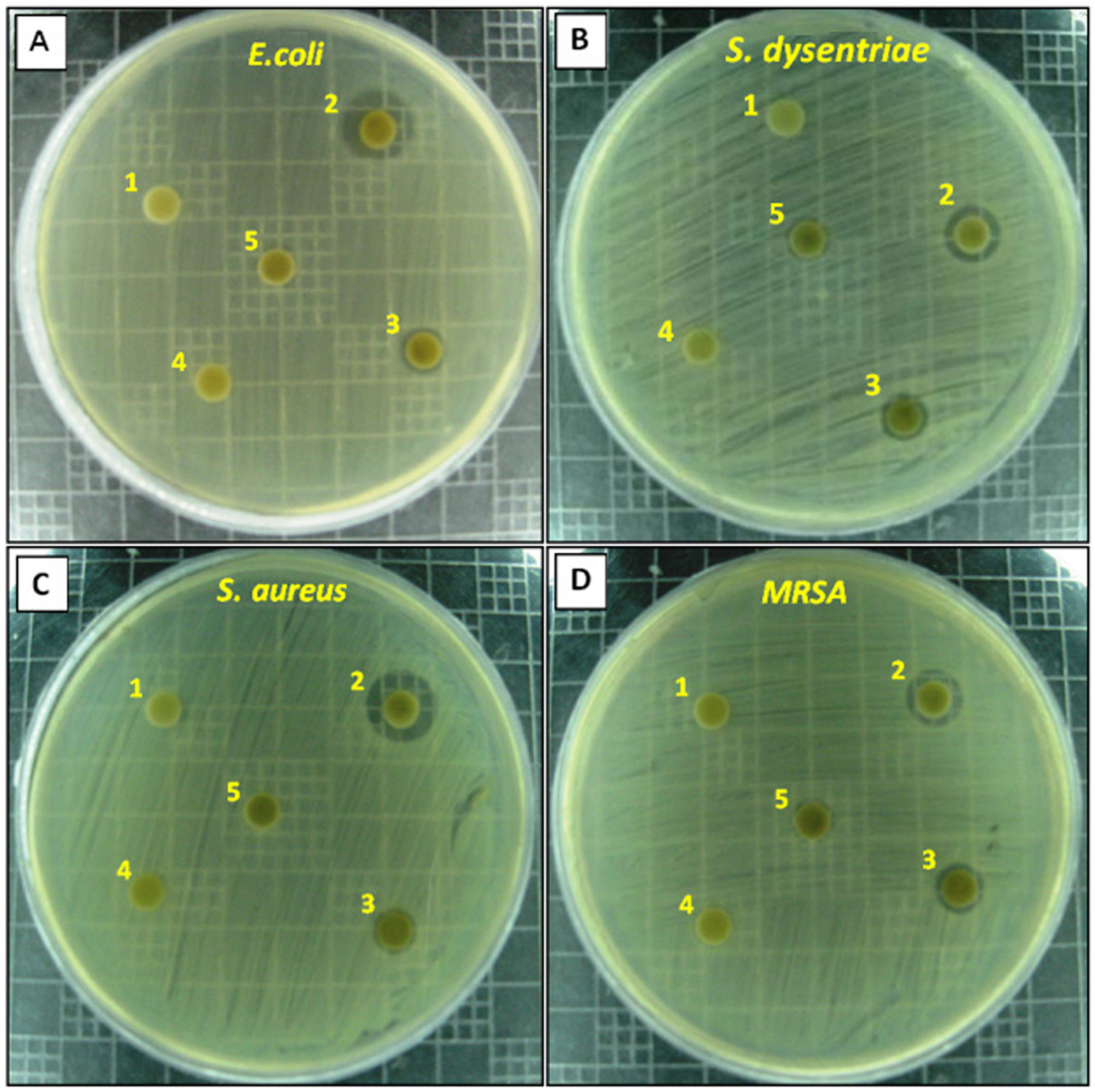

Figure 9 Comparison of the inhibition zone test between Gram-negative and Gram-positive bacteria (ie, E. coli [A], S. dysentriae [B], S. aureus [C], and MRSA [D]) form zeolite, A0, AI, A2, and A5 (I-5), respectively.

Abbreviations: E. coli, Escherichia coli; MRSA, methicillin-resistant Staphylococcus aureus; S. dysentriae, Shigella dysentriae.

Table 2 Average inhibition zone and standard deviation for zeolite, $\mathrm{AgNO}_{3}$ /zeolite (A0,) and $\mathrm{Ag} /$ zeolite at different $\mathrm{AgNO}_{3}$ concentrations: A2 1.0\%, A4 2.0\%, and A5 5.0\%

\begin{tabular}{|c|c|c|c|c|c|c|c|}
\hline \multirow[t]{2}{*}{ Bacteria } & \multicolumn{4}{|c|}{ Inhibition zone (mm) } & \multirow[t]{2}{*}{$\begin{array}{l}\text { Control negative }(\mathrm{mm}) \\
\text { zeolite }(10 \mathrm{mg} / \mathrm{ml})\end{array}$} & \multicolumn{2}{|c|}{$\begin{array}{l}\text { Control positive } \\
(\mathrm{mm})\end{array}$} \\
\hline & AO & $\mathbf{A 2}$ & A4 & A5 & & СTX & C \\
\hline E. coli & $12.52 \pm 0.14$ & $7.87 \pm 0.22$ & $6.44 \pm 0.08$ & $7.40 \pm 0.16$ & NA & 21.80 & 16.71 \\
\hline S. dysentriae & $9.03 \pm 0.05$ & $7.52 \pm 0.18$ & $6.48 \pm 0.19$ & $6.95 \pm 0.32$ & NA & 23.22 & 19.41 \\
\hline S. aureus & $12.08 \pm 0.30$ & $7.40 \pm 0.05$ & $6.53 \pm 0.47$ & $6.13 \pm 0.22$ & NA & 23.60 & 16.43 \\
\hline MRSA & $9.43 \pm 0.19$ & $8.16 \pm 0.09$ & $6.92 \pm 0.14$ & $7.04 \pm 0.25$ & NA & 18.89 & 15.48 \\
\hline
\end{tabular}

Abbreviations: C, chloramphenicol; CTX, cefotaxime; E. coli, Escherichia coli; MRSA, methicillin-resistant Staphylococcus aureus; NA, not appearing; S. aureus, Staphylococcus aureus; S. dysentriae, Shigella dysentriae. 
thus, Ag NPs in contact with bacteria gradually release silver ions. ${ }^{26,27}$ The diameters of the inhibition zone in the agar plate are given in millimeters. The tests were repeated three times for each treated sample, and the results are presented in Table 2. The $10 \mathrm{mg} / \mathrm{mL}$ zeolite suspensions did not show any antibacterial activity. The $\mathrm{AgNO}_{3}$ /zeolite suspension for all tested bacteria showed high antibacterial activity; interestingly, these effects in the Ag/zeolite NCs (A2, A4, and A5) increased with the decreasing size of Ag NPs. However, other analysis in this research showed that the amounts of Ag NPs gradually increased, but higher Ag NPs loadings did not lead to superior antibacterial activity.

\section{Conclusion}

Uniform size of the Ag NPs was successfully achieved from the $\mathrm{AgNO}_{3}$ /zeolite at different $\mathrm{AgNO}_{3}$ concentrations using sodium borohydride as a chemical reduction agent in the isometric cavities of the zeolite framework without any heat treatment. The average diameters and standard deviations of the Ag NPs for Ag/zeolite NCs were around $2.12 \pm 0.37 \mathrm{~nm}$, $2.95 \pm 0.65 \mathrm{~nm}$, and $3.11 \pm 0.88 \mathrm{~nm}$ for A2, A4, and A5, respectively. Thus, at different concentrations of $\mathrm{AgNO}_{3}$, larger Ag NPs were obtained when the silver ion concentration increased. Moreover, the PXRD analysis confirmed that the crystallographic planes of the silver crystal were fcc types. The UV-visible absorption spectra show the peak characteristic of the SPR bond of Ag NPs, and the SEM images show that the morphology for zeolite and Ag/zeolite NCs (A2, A4, and A5) demonstrates cubic shapes with no noteworthy morphological distinctions between them. Also, due to the presence of Ag NPs in the external surfaces of zeolite, these planes gradually become shinier. Furthermore, EDXRF spectra confirm the presence of elemental compounds in the zeolite and Ag NPs without any contamination peaks. The Ag/zeolite NCs at different particle sizes of Ag NPs show antibacterial activity against the Gram-positive and Gramnegative bacteria test in this study. These results show that the antibacterial susceptibility of Ag NPs in zeolite can be changed with the size and concentration of Ag NPs and that it decreases with the increase in the particle size. Further studies will investigate the bactericidal effects of Ag/zeolite NCs on the types of bacteria for potential widening of this subject area, such as coating, drinking water, and biomedical production.

\section{Acknowledgements}

The authors are grateful to the staff of the Department of Chemistry, Institute of Bioscience (IBS/UPM), Malaysia, and also to Mrs Parvaneh Shabanzadeh and Mrs Pn Zahidah Muhamed, who contributed to this work.

\section{Disclosure}

The authors have no conflicts of interest to disclose in this work.

\section{References}

1. Huwe H, Fröba M. Synthesis and characterization of transition metal and metal oxide anoparticles inside mesoporous carbon CMK-3. Carbon. 2007;45:304-314.

2. Rai M, Yadav A, Gade A. Silver nanoparticles as a new generation of antimicrobials. Biotechnol Adv. 2009;27:76-83.

3. Evanoff DD Jr, Chumanov G. Synthesis and optical properties of silver nanoparticles and arrays. Chem Phy sChem. 2005;6(7):1221-1231.

4. Balan L, Burget D. Synthesis of metal/polymer nanocomposite by UV-radiation curing. Eur Polym J. 2006;42(12):3180-3189.

5. Luechinger NA, Grass RN, Athanassiou EK, Stark WJ. Bottom-up fabrication of metal/metal nanocomposites from nanoparticles of immiscible metals. Chem Mater. 2010;22:155-160.

6. Takacs L. Metal-metal oxide systems for nanocomposite formation by reaction milling. Nanostruct Mater. 1998;2(3):241-249.

7. Shameli K, Ahmad MB, Yunus WMZW, et al. Synthesis of silver/ montmorillonite nanocomposites using $\gamma$-irradiation. Int J Nanomedicine. 2010;5:1067-1077.

8. Shameli K, Ahmad MB, Yunus WMZW, et al. Synthesis and characterization of silver/talc nanocomposites using the wet chemical reduction method. Int J Nanomedicine. 2010;5:743-751.

9. Talebi J, Halladj R, Askari S. Sonochemical synthesis of silver nanoparticles in Y-zeolite substrate. J Mater Sci. 2010;45:3318-3324.

10. Viertelhaus M, Taylor AE, Kloo L, et al. Silver nitrate in silver zeolite A: three-dimensional incommensurate guest ordering in a zeolite framework. Dalton Trans. 2006:2368-2373.

11. Zhang W, Qiao X, Chen J. Synthesis of silver nanoparticles-effect of concerned parameters in water/oil microemulsion. Mater Sci Eng B. 2007;142(25):1-15.

12. Grobet PJ, Schoonheydt RA. ESR on silver clusters in zeolite A. Surf Sci. 1985;156(2):893-898.

13. Gurin VS, Petranovskii VP, Hernandez MA, et al. Silver and copper clusters and small particles stabilized within nanoporous silicate-based materials. Mater Sci Eng A. 2005;391(1-2):71-76.

14. Tsutsumi K, Takahashi H. The formation of metallic silver in silverform zeolites. Bull Chem Soc Jpn. 1972;45(8):2332-2337.

15. Beer R, Calzarferri G, Li J, et al. Towards artificial photosynthesis: experiments with silver zeolites, part 2. Coordin Chem Rev. 1991;111: 193-200.

16. Sharma VK, Yngard RA, LIN Y. Silver nanoparticles: green synthesis and their antibacterial activities. Adv Colloid Interface Sci. 2009;145:83-96.

17. Shameli K, Ahmad MB, Yunus WMZW, et al. Green synthesis of silver/ montmorillonite/chitosan bionanocomposites using the UV irradiation method and evaluation of antibacterial activity. Int $J$ Nanomedicine. 2010;5:875-887.

18. Ahmad MB, Shameli K, Yunus WMZW, et al. Synthesis and antibacterial activity of silver/montmorillonite nanocomposites. Res J Biol Sci. 2009;4(9):1032-1036.

19. Pal S, Tak YK, Song JM. Does the antibacterial activity of silver nanoparticles depend on the shape of the nanoparticle? A study of the Gram-negative bacterium Escherichia coli. Appl Environ Microbiol. 2007;73:1712-1720.

20. Holt KB, Bard AJ. Interaction of silver (I) ions with the respiratory chain of Escherichia coli: an electrochemical and scanning electrochemical microscopy study of the antimicrobial mechanism of micromolar $\mathrm{Ag}^{+}$. Biochemistry. 2005;44:13214-13223. 
21. Song KC, Lee MS, Park TS, et al. Preparation of colloidal silver nanoparticles by chemical reduction method. Korean J Chem Eng. 2009; 26(1):153-155.

22. Aihara N, Torigoe K, Esumi K. Preparation and characterization of gold and silver nanoparticles in layered laponite suspensions. Langmuir. 1998:14:4945-4949.

23. Liu Z, Wang H, Wang LX. Red shift of plasmon resonance frequency due to the interacting $\mathrm{Ag}$ nanoparticle embedded in single crystal $\mathrm{SiO}_{2}$ by implantation. Applied Phys Lett. 1998;72:1823-1825.

24. Bar H, Bhui DK, Sahoo GP, et al. Green synthesis of silver nanoparticles using latex of Jatropha curcas. Colloid Surface A. 2009;339:134-139.
25. Benn TM, Westerhoff P. Nanoparticle silver released into water from commercially available sock fabrics. Environ Sci Technol. 2008;42: 4133-4139.

26. Morones JR, Elechiguerra JL, Camacho A, et al. The bactericidal effect of silver nanoparticles. Nanotechnology. 2005;16:2346-2353.

27. Lee D, Cohen RE, Rubner MF. Antibacterial properties of Ag nanoparticle loaded multilayers and formation of magnetically directed antibacterial microparticles. Langmuir. 2005;21:9651-9659.
International Journal of Nanomedicine

\section{Publish your work in this journal}

The International Journal of Nanomedicine is an international, peerreviewed journal focusing on the application of nanotechnology in diagnostics, therapeutics, and drug delivery systems throughout the biomedical field. This journal is indexed on PubMed Central,

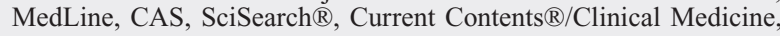

\section{Dovepress}

Journal Citation Reports/Science Edition, EMBase, Scopus and the Elsevier Bibliographic databases. The manuscript management system is completely online and includes a very quick and fair peer-review system, which is all easy to use. Visit http://www.dovepress.com/ testimonials.php to read real quotes from published authors.

Submit your manuscript here: http://www.dovepress.com/international-journal-of-nanomedicine-journal 